Revista da Sociedade Brasileira de Medicina Tropical

Journal of the Brazilian Society of Tropical Medicine

Vol.:52:e-20180063: 2019

doi: 10.1590/0037-8682-0063-2018

\title{
Letter
}

\section{Prevention of zoonotic diseases in immunocompromised patients: a neglected question}

\author{
Andréa de Lima Rodrigues Alves Pereira ${ }^{[1]}$, Maria Rita Donalísio Cordeiro[1] \\ and Rodrigo Nogueira Angerami ${ }^{[2]}$
}

\author{
[1]. Universidade Estadual de Campinas, Faculdade de Ciências Médicas, Campinas, SP, Brasil. \\ [2]. Universidade Estadual de Campinas, Faculdade de Ciências Médicas, Secretaria de Saúde de Campinas, Campinas, SP, Brasil.
}

\section{Dear Editor:}

A recent study published in the Revista Brasileira de Medicina Tropical by Coutinho et al highlighted the impact of American visceral leishmaniasis (AVL) on patients living with human immunodeficiency virus infection and acquired immune deficiency syndrome (HIV/AIDS); they highlighted both the high potential for morbidity and mortality and the challenges related to therapeutic management in this patient group $^{1}$. However, although there is a growing concern regarding diagnosis and treatment of AVL in this specific population, the current approaches and recommendations regarding prevention of not only AVL but also other zoonotic diseasesdiseases transmitted naturally from animals to humans-in immunocompromised patients also deserve attention; physicians as well as other health professionals such as veterinarians need to pay attention to this issue 2 .

AVL is a classic example of a zoonotic disease and its importance as a major public health challenge with respect to control and prevention is well known ${ }^{3}$. The expansion of transmission areas such as large urban settlements adds to this issue. In such scenarios, humans are often exposed to potential reservoir animals or animal hosts in various situations, including workplace, diet, and household. Irrespective of the cause, immunocompromised individuals present both a higher risk of infection and greater potential for more severe clinical course ${ }^{4,5}$. The profile of patients living with HIV/AIDS and illness (AVL) studied by Coutinho et al. is just one of the innumerable possible immunocompromised-zoonosis binomials ${ }^{1}$. The number of immunocompromised patients is increasing due to factors

Corresponding author: Andréa de Lima Rodrigues Alves Pereira. ORCID: 0000-0002-7886-4541 e-mail: andrea.alves.vet@gmail.com

Received 15 February 2018

Accepted 13 October 2018 such as increase in number of transplants and therapeutic approaches with biological and chemotherapeutic agents. In addition, more than 200 zoonotic diseases are known to affect humans; due to climatic, environmental, and behavioral factors, many of these present great potential for (re)emergence and endemic establishment. A number of zoonotic diseases that affect immunocompromised individuals have been described, including campylobacteriosis, salmonellosis, bartonellosis, pasteurellosis, leptospirosis, brucellosis, cryptosporidiosis, giardiasis, toxoplasmosis, sporotrichosis, histoplasmosis, cryptococcosis, and rhodococcosis ${ }^{6,7}$. Some diseases such as cryptococcosis (extrapulmonary form), chronic intestinal cryptosporidiosis, salmonellosis (non-typhoid), cerebral toxoplasmosis, and Chagas' disease (reactivated form) are also included in the Centers for Disease Control and Prevention (CDC) criterion that was adapted from the definition of AIDS ${ }^{8}$.

In this context, except for studies on HIV-Chagas' disease and HIV-AVL, robust and updated information on the prevalence and impact of other zoonotic diseases among immunocompromised individuals is scarce or even absent in some endemic countries. The Clinical Protocols and Therapeutic Guidelines for Management of HIV Infection in Current Adults only recommend primary and secondary prophylaxis for some opportunistic infections, including toxoplasmosis and cryptococcosis, but do not offer general or specific recommendations for prevention of the majority of zoonotic infections ${ }^{9}$. The risk of Cryptosporidium, Bartonella, and Sporothrix infection due to living with pets, consumption of fresh milk products in natura and eventual Brucella contamination, contact with horses and potential exposure to Rhodococcus equi, environments with excreta of bats and birds, and presence of Histoplasma and Cryptococcus are just a few examples of not infrequent risk situations encountered by immunocompromised individuals; little attention is paid to this issue in either clinical practice or in recommendations for guidelines and protocols ${ }^{7}$. 
With respect to the effect of zoonotic infections on human health, much information is not available for these vulnerable individuals; there are few recommendations for care for this group of patients. In a scenario where endemic or emerging zoonotic diseases remain a challenge to public health and where the number of immunocompromised patients is progressively increasing, reducing infection risk is one of the main strategies for minimizing the morbidity and mortality associated with zoonotic infections ${ }^{10}$.

The One Health principles should be a guiding element in the logic of knowledge-practice-attitude by those involved in drawing up recommendations in clinical protocols and guidelines. In addition, those responsible for healthcare of immunocompromised patients should not restrict themselves to only patients living with HIV/AIDS ${ }^{11}$. An additional strategy might be the involvement of veterinary professionals in the prevention of zoonotic diseases in the human population with respect to different scenarios such as clinical practice for domestic and sylvatic pets, consultation in the food production chain, and multidisciplinary public health programs. This, in addition to the current medical practice recommendations and protocols, would help improve the efficacy of prevention of zoonotic diseases among (but not only) immunocompromised patients ${ }^{12}$. Thus, it is expected that medical-scientific entities, including the Brazilian Society of Tropical Medicine, that are active in the dissemination of studies and research, in promotion of technicalscientific discussions, and especially in elaboration of specific clinical protocols and guidelines, will consider the subject of multidisciplinary approaches for prevention of zoonosis among the immunocompromised population in different scenarios.

Conflict of Interest: The authors declare that there is no conflict of interest.

Financial support: This study was financed in part by the Coordenação de Aperfeiçoamento de Pessoal de Nivel Superior - Brasil (CAPES) - Finance Code 001.

\section{REFERENCES}

1. Coutinho JVSC, dos Santos FS, Ribeiro RSP, Oliveira IBB, Dantas VB, Santos ABFS, et al. Visceral leishmaniasis and leishmaniasis-
HIV coinfection: comparative study. Rev Soc Bras Med Trop. 2017;50(5):670-4.

2. Robinson RA, Pugh RN. Dogs, zoonoses and immunosuppression. J R Soc Promot Health. 2002;122(2):95-8.

3. Morais MHF, Fiuza VOP, Araújo VEM, Menezes FC, Carneiro M. Avaliação das atividades de controle da leishmaniose visceral em Belo Horizonte, Minas Gerais, 2006-2011. Epidemiol Serv Saude. 2015;24(3):485-96.

4. Seimenis AM. The spread of zoonoses and other infectious diseases through the international trade of animals and animal products. Vet Ital. 2008;44(4):591-9.

5. López J, Peña A, Pérez R, Abarca K. Tenencia de mascotas en pacientes imunocomprometidos: actualización y consideraciones veterinarias y médicas. Rev Chilena Infectol. 2013;30(1):52-62.

6. Mani I, Maguire JH. Small animal zoonoses and immuncompromised pet owners. Top Companion Anim Med. 2009;24(4):164-74.

7. Stull JW, Stevenson KB. Zoonotic diseases risk for immunocompromised and other high-risk clients and staff promoting safe pet ownership and contact. Vet Clin North Am Small Anim Pract. 2015;45(2):377-92.

8. Ministério da Saúde / Secretaria de Políticas de Saúde / Coordenação Nacional de DST e Aids. Revisão da definição nacional de casos de Aids em indivíduos com 13 anos ou mais, para fins de Vigilância Epidemiológica [Internet]. Brasília: Ministério da Saúde, 1998. Disponível em: http://bvsms.saude.gov.br/bvs/ publicacoes/074_02revisao.pdf.

9. Ministério da Saúde. Protocolo Clínico e Diretrizes Terapêuticas para Manejo da Infecção pelo HIV em adultos [Internet]. Brasília: Ministério da Saúde, 2017. Disponível em: http://www.aids.gov.br/ pt-br/pub/2013/protocolo-clinico-e-diretrizes-terapeuticas-paramanejo-da-infeccao-pelo-hiv-em-adultos.

10. Gurry GA, Campion V, Premawardena C, Woolley I, Shortt J, Bowden DK, et al. High rates of potentially infectious exposures between immunocompromised patients and their companion animals: an unmet need for education. Intern Med J. 2017;47(3):33335.

11. One Health. One Health initiative [Internet]. USA: One Health, 2018. Disponível em: http://www.onehealthinitiative.com/index. php.

12. Davis RG. HIV/AIDS Education: Still an important issue for veterinarians. Public Health Rep. 2008;123(3):266-75. 